\title{
O SISTEMA FAMILIAR E OS PROBLEMAS DAS DROGAS: um estudo do filme Cazuza - O Tempo Não Para
}

DOI: $10.22289 / 2446-922 X . V 3 N 2 A 7$

Tamiris Carla Gonçalves ${ }^{1}$

Gilmar Antoniassi Junior

\section{RESUMO}

A família é determinante na criação de condições para que vínculos sociais se formem, sendo compreendida, conforme a perspectiva sistêmica, como a "matriz de identidade" que envolve gerações, divisões e fenômenos vinculados ao ciclo de vida familiar e à história transgeracional. A Psicologia Sistêmica defende que há o envolvimento de todos os entes familiares quando uma pessoa deste núcleo está passando por algum conflito. A família possui função reguladora do sistema, oferecendo suporte para a superação individual. O objetivo deste estudo é refletir o sistema familiar e os contratempos familiares no caso de possuir um filho adicto, à luz do filme Cazuza - O Tempo Não Para. Utilizou-se um delineamento qualitativo de estudo de caso de natureza descritiva histórica através do método de história de vida, mediante a narrativa do filme 'Cazuza - O Tempo não Para', cinebiografia, dirigida por Sandra Werneck e Walter Carvalho. Este caso mostra como a família pode influenciar o indivíduo a procurar atividades ilícitas. Atitudes como a superproteção materna e a omissão paterna, o acesso fácil a dinheiro, dentre outros, incidiram em atitudes rebeldes por parte de Cazuza. O uso de narcóticos foi determinante para que vivesse uma intensa vida boêmia e não se prevenisse, contraindo o vírus HIV. O trabalho social conjunto, com o intuito de preservar a instituição familiar, é primordial para que as drogas não desestruturem mais toda comunidade. O exemplo de Cazuza deve ser recordado, para que não aconteça com outros inúmeros brasileiros. Necessária se faz a atuação do psicólogo com todos os membros da família, não só o usuário, visto que as consequências do uso de narcóticos atingem a cada ente familiar de forma específica.

Palavras-chave: Drogas; Família; Sistema.

\section{ABSTRACT}

The family is determinant in creating the conditions for social bonds to be formed, being understood, according to the systemic perspective, as the "identity matrix" that involves generations, divisions and phenomena linked to the family life cycle and transgenerational history. Systemic Psychology argues that there is the involvement of all family entities when a person of this nucleus is going through some conflict. The family has a regulatory function of the system, offering support for individual overcoming. The objective of this study is to reflect

\footnotetext{
${ }^{1}$ Endereço eletrônico de contato: tamiriscarla0810@gmail.com

Recebido em 18/09/2017. Aprovado pelo conselho editorial para publicação em 31/10/2017.
}

Rev. Psicol Saúde e Debate. Dez., 2017:3(2):74-89. 
the family system and the family setbacks in the case of having an addict child, in the light of the film Cazuza - O Tempo Não Para. We used a qualitative delineation of a case study of historical descriptive nature through the method of life history, through the narrative of the film 'Cazuza - O Tempo não Para', a biography, directed by Sandra Werneck and Walter Carvalho. This case shows how the family can influence the individual to seek illicit activities. Attitudes such as maternal overprotection and paternal omission, easy access to money, among others, focused on rebellious attitudes on the part of Cazuza. The use of narcotics was determinant for him to live an intense bohemian life and not to be foreseen, contracting the HIV virus. Joint social work, with the intention of preserving the family institution, is essential so that drugs do not further disrupt every community. The example of Cazuza must be remembered, lest it happen to countless other Brazilians. It is necessary to perform the psychologist with all family members, not only the user, since the consequences of the use of narcotics affect each family entity in a specific way.

Keywords: Drugs; Family; System.

\section{INTRODUÇÃO}

O Sistema Familiar é um conjunto de pessoas, inseridas em sociedade e aptas a viver em diferentes tipos de arranjos. Basicamente, tem-se a função de socialização. A família exerce papel importante na criação de condições para que se estabeleçam os vínculos sociais. O conjunto de pessoas que se relacionam na sociedade constitui sistematicamente a função básica dos arranjos denominados sistema familiar. Os problemas das drogas têm afetado as relações familiares, sendo a família um preditor de risco e proteção para o uso e/ou abuso das drogas, vez que é um dos elos mais fortes (Schenker \& Minayo, 2003).

Na perspectiva sistêmica, a família é compreendida como a "matriz de identidade" envolve gerações, divisões e fenômenos que estão vinculados ao ciclo de vida familiar e à história transgeracional, ou seja, a transmissão psíquica imposta a cada um, desde o nascimento, através dos vínculos constituídos a partir do legado herdado daqueles que o precedem, com a riqueza dos costumes e tradições. Integrando a partir da identidade de cada indivíduo uma construção prioritária do núcleo familiar, formando matriz de identidade (Penso \& Subdrack, 2004).

A matriz de identidade é a representação da rede de relações primária, que envolve a criança desde o conhecimento que tem dos pais, incluindo determinantes biológicas, psicológicas e socioculturais. Assim, esta matriz compreende o processo de aprendizagem relacional da criança. A matriz de identidade é constituída por um primeiro e segundo universo: no primeiro, a criança não diferencia pessoas de objetos, não distingue fantasia de realidade; o segundo universo caracteriza-se quando a criança vivencia a separação entre fantasia e realidade, existindo uma distinção entre o Eu e o Outro (Fonseca, 2012).

Rev. Psicol Saúde e Debate. Dez., 2017:3(2):74-89. 
A Psicologia Sistêmica determina que quando uma pessoa da família está passando por algum conflito em sua vida, todos os membros familiares são envolvidos no conflito, sendo que os membros da família exercem função reguladora do sistema. Assim, oferecem suporte uns aos outros para que possam superar "crises", sem que mesmo nenhuma mudança real ocorra (Penso \& Subdrack, 2004).

É primordial que os vínculos familiares estejam fidelizados, ou seja, que as ligações entre pais, filhos, irmãos, bem como com os demais membros familiares, estejam alicerçadas de maneira que fatores negativos não ameacem e desvirtuem o seio familiar.

Estudos revelam que a chegada da adolescência é um dos momentos propícios para o uso de drogas, o qual surge como um dos sintomas denunciantes das dificuldades familiares pelo percurso dos ciclos da vida. O adolescente necessita desenvolver a autonomia e a independência do grupo familiar; entretanto, a presença da família é necessária, visto que o momento implica em crescimento e individualização, mas requer um norte de percepção para a direção de novos rumos (Penso \& Subdrack, 2004).

A adolescência é um momento de diferenciação, no qual naturalmente o jovem afastase de sua família e adere ao seu grupo de iguais. Neste distanciamento do sistema familiar é que muitas vezes os membros da família não percebem a necessidade de estar por perto para acompanhar quais os sistemas exteriores ao núcleo familiar relacionando-se com aquele membro (Marques \& Cruz, 2000).

Este momento é oportuno para o envolvimento com as substâncias psicoativas, diante dos conflitos do ciclo da vida, a necessidade das descobertas que surgem e a onipotência que assombra. Se este grupo estiver usando drogas, pressioná-lo-á a usar também. Entrando em contato com tais substâncias, o adolescente está expondo-se a inúmeros riscos (Fonseca, 2012; Marques \& Cruz, 2000).

O uso abusivo das drogas altera o comportamento rotineiro e expõe a riscos sociais e de saúde, estando mais vulnerável a atos violentos, perca do emprego, amigos e mais propício ao adoecimento, além de afetar todo seu entorno, principalmente a família (Padilha, 2011).

A terapia familiar apresenta-se como um fator que contribui para uma melhor relação da família com o dependente. Padilha (2011), assevera que o objetivo do terapeuta familiar é ajudar a família a compreender os sintomas do paciente, a harmonia dentro daquele núcleo específico. No mesmo sentido: "Através das terapias familiares é possível a construção de um sistema terapêutico que requalifica os pais em sua função educativa, permitindo reflexão à família sobre suas próprias competências, auxiliando-as na auto solução" (Orth, 2005).

O presente estudo justifica-se pela necessidade de compreender os efeitos sociais do uso das drogas, através da esfera familiar. Ademais, é preciso analisar como os arranjos 
familiares contribuem para que o indivíduo comece a fazer uso de psicoativos, visto que ações ou omissões dos pais e demais familiares são definidoras de diversas condutas do usuário.

O objetivo é refletir o sistema familiar e os contratempos familiares no caso de possuir um filho adicto, à luz do filme Cazuza - O Tempo Não Para.

\section{METODOLOGIA}

Utilizou-se um delineamento qualitativo de estudo de caso de natureza descritiva histórica através do método de história de vida, mediante a história narrada no filme 'Cazuza - O Tempo não Para'. Trata-se de uma comovente cinebiografia de um dos maiores ídolos do rock nacional, dirigida por Sandra Werneck e Walter Carvalho, mostra alguns dos amores do roqueiro, morto em 1990 após contrair AIDS (Werneck \& Carvalho, 2004).

A escolha do filme se deu devido o filme mostrar a relação do filho adito com os pais, e seus contratempos ao longo da vida familiar e social - sua relação com os companheiros do Barão Vermelho; o envolvimento com as drogas; o processo de composição de alguns clássicos do rock nacional; e a luta do compositor contra a doença. O enredo do filme possui note no livro 'Cazuza, Só As Mães São Felizes' escrito pela mãe do cantor Lucinha Araújo, e pela jornalista Regina Echeverria. O livro relata todos os fatos marcantes de sua vida com seu único filho, morto em 1990, em consequência da Aids. Além de revelar detalhes sobre sua trajetória e sua relação familiar. Adaptada para o cinema em 2004 (Araújo \& Echeverria, 2016). Ressaltando que por se tratar de uma obra aberta, não necessitou de aprovação do comitê de ética e pesquisa com seres humanos.

Os achados foram analisados, corroborados através da obsenvação do fenômeno envolvido - o envolvimento com as drogas - a dinâmica familiar - o contexto social e de vida - os danos à saúde. A fim de apreciar o tio de família quanto a estrutura - dinâmica e as relações parentais; o sistema familiar quanto as drogas e o HIV; o envolvimento do sistema familiar no enfrentamento dos danos à saúde motivado pelo consumo da droga.

Levou-se em consideração o referencial teórico dos autores da Psicologia Sistêmica como - Murray Bowen, Salvador Minuchin e as publicações decorrentes no período compreendido de 1980 a 2016. Para a identificação o tipo familiar tomou-se como base o Roteiro de Tipologia Familiar proposto por Caniço, Bairrada, Rodrigues \& Carvalho (2010), levando em conta a identificação da presença das variáveis descritas no quadro 1 em anexo.

Rev. Psicol Saúde e Debate. Dez., 2017:3(2):74-89. 


\section{CAZUZA O TEMPO NÃO PÁRA - BREVE RELATO DO FILME}

Um jovem muito maquiado canta uma música em inglês sob a lona do Circo Voador. Instável e desafiador, mas também extremamente sedutor, Cazuza vivia sua confortável vida de garoto da Zona Sul sob a cerrada vigilância da mãe. Queria, queria tudo - ao mesmo tempo, em um agora permanente. A urgência transgressora pertencente a sua pessoa não conhecia limites e se refletia em todas as áreas de sua vida - afetiva, as novas experiências, o amor pelo perigo, a criação artística. Logo descobriu que a música era a melhor maneira de se expressar. Cazuza vivia tudo ao mesmo tempo ao lado de seus companheiros eclética e heterogêneos, refletido em vários lados de sua própria personalidade. $O$ encontro com 0 guitarrista Roberto Frejat, o baixista Dé, o baterista Guto Gofi, o tecladista Maurício - pessoas de sua idade à procura de um novo som - foi a primeira etapa da vitoriosa carreira. Juntos viajaram e conheceram o Brasil, vivendo novos afetos. Para atenuar a intensificação de conflitos familiares, é intimado a trabalhar com o pai, diretor de uma gravadora, onde conhece Zeca, produtor musical experiente, que se transforma em uma espécie de guru que the apresenta ao núcleo artístico de compositores e poetas. O jovem inquieto passa a surpreender com letras densas e poéticas que definiam sentimentos, ideias para geração. $O$ sucesso não domesticou as arestas do novo ídolo. Viver cada vez mais intensamente, romper limites, o uso exagerado de drogas, correr todos os riscos fazia pare de seu cotidiano, monitorado, na medida do possível, por uma mãe atenta e preocupada, mas também orgulhosa do talento do filho que adorava acima de tudo. O diagnóstico de que era portador do vírus HIV foi recebido pelo jovem com desespero, seguido da busca de novas formas de tratamento para uma doença que na época representava uma sentença de morte a curtíssimo prazo. E Cazuza morreu em 1990 aos 32 anos (Werneck \& Carvalho, 2004).

\section{ANÁLISE E DISCUSSÃO}

A família, proveniente do latim familus, que significa servidor, evolui de acordo com culturas, tradição, contexto político, social e econômico. Mantém critérios constantes pela aliança (forma de relação que significa modo de afinidade e união conjugal) e pela filiação (modo de descendência). Uma determinada família não é do tipo $A$, dogmaticamente. Será neste momento do tipo $\mathrm{A}$, podendo evoluir para o tipo $\mathrm{B}$ e com determinada probabilidade de evoluir para o tipo C, D ou E, talvez ainda com características simultâneas dos diversos tipos (Caniço, Bairrada, Rodrigues \& Carvalho, 2010). 
A partir do filme delineado que retrata a vida de Cazuza identifica-se na tipologia familiar enquanto estrutura e dinâmica características da família nuclear, esta é a típica família com uma só união entre adultos e um só nível de descendência, ou seja, pai e mãe e o seu filho. É também conceituada como família simples. Classifica-se como de grande estabilidade, de fato, tradição ou sociedade. Entretanto, a dinâmica familiar e os sinais e pistas que alertem para a disfuncionalidade são intencionalmente camuflados por diferentes elementos da família. Os padrões de comportamentos e estilos de vida não saudável devem ser detectados e corrigidos (Caniço, Bairrada, Rodrigues \& Carvalho, 2010).

No filme passa-se entre os pais de Cazuza e a relação deste com seus amigos. Não são detectados outros personagens com níveis de parentesco. Importante retratar que ele era filho único, como o que pode ser assimilado nesta passagem em uma das primeiras cenas do filme:

A mãe de Cazuza, está dentro de um táxi a procura de seu filho, que anda loucamente em seu carro pelas ruas, com seu novos companheiros de banda. O taxista, vendo a agonia daquela mãe, indaga: "Ô Dona, a senhora me desculpe. Mas será que ele já não voltou pra casa?" "Tenho certeza que não." "Sabe dona, eu tenho quatro filhos. Às vezes eles dão uma sumidinha mas..." "É, mas eu não, só tenho esse".

A família baseada no casamento monogâmico era considerada como instituição de louvor e carinho, o que permanece nos dias atuais, predominando em toda comunidade. Lévis-Strauss (1956) assevera que a família, consistindo em uma união, mais ou menos duradoura, socialmente aprovada, entre um homem, uma mulher e seus filhos, constitui fenômeno universal presente em todo e qualquer tipo de sociedade. Observa-se que grande parte das pessoas que constituem uma nova família, o fazem nos mesmos moldes da família nuclear; comumente o ex-cônjuge constitui uma nova união, sendo que desta junção surgem os filhos do novo casal. Hodiernamente, o modelo tradicional de família é caracterizado juntamente com diversos outros modelos, que são alterações advindas das mudanças sociais no decorrer do tempo. Há famílias que não chegam a ter o número de integrantes da família nuclear, sendo formadas por casal sem filhos, irmãos que vivem juntos ou uma pessoa sozinha (Oliveira, 2009).

Nos últimos anos, ocorreu uma minimização sistemática do tamanho das famílias, mudando a estrutura familiar e a frequência com que os casais têm apenas um filho. De modo histórico, o filho único é estigmatizado como aquele que recebe excessiva atenção, 
amadurecendo precocemente e, pela falta de mais crianças com as quais teria que dividir aspectos materiais e emotivos, torna-se egoísta, dependente e temperamental ao ser comparado com os demais de sua idade. Entretanto, estudos apontam que os filhos únicos não apresentam traços negativos de personalidade; pelo contrário, possuem tantos amigos quanto as crianças que possuem irmãos, exercem traços de liderança e autoestima mais elevada. Em estudo realizado entre adolescentes de todo o Brasil, os investigados demonstraram um padrão similar para comportamentos como tabagismo, uso de entorpecentes, bebidas alcoólicas e opção sexual. A diferença consiste na característica que os filhos únicos apresentam traços de filhos primogênitos, destacando-se no desempenho escolar e no bom relacionamento com os pais (Tavares, Fuchs, Diligenti, Abreu, Rodhe \& Fuchs, 2004).

A tendência da população feminina em preocupar-se com a carreira profissional ao invés do casamento, contribui para a redução dos anos dedicados à criação da prole, sendo considerado fator determinante na tomada de decisão em ter mais de um filho, ou até mesmo não ter nenhum. As donas de casa, que permanecem o tempo todo com os filhos, possuem mais tempo para dar-lhes atenção; desta forma, a mulher com um único filho teria mais oportunidade para super protegê-lo. No tocante às poucas diferenças existentes entre as crianças com irmãos e o filho único, existem fatores que contribuem para a escolha de uma prole menor, como a situação socioeconômica e o tempo que os genitores possuem para interação (Freitas, 2008).

No entanto, o núcleo estrutural e de dinâmica da família não deixa de expressar uma Família com dependente - onde um dos elementos é particularmente dependente dos cuidados de outros, por motivo de doença, excluindo-se o caso de crianças saudáveis. Tratase de famílias com necessidade de ajustamento de papéis para responder à sobrecarga física, emocional e em tempo, o que pode ser melhor ou pior conseguido (Caniço, Bairrada, Rodrigues \& Carvalho, 2010).

Evidenciado pela dinâmica da família de Cazuza que é totalmente modificada, desde que a AIDS é detectada em seu corpo. Além do desgaste físico, o emocional é relevante. Quem acompanha todo o tratamento de perto é a mãe. Inclusive, os pais passam extensas temporadas em Boston (EUA) para proporcionar tratamento avançado ao filho. É notável como Cazuza é próximo de sua mãe, sendo ela todo seu esteio para a luta contra a doença.

A relação simbiótica é o fenômeno que ocorre quando um dos indivíduos utiliza dois estados de Ego e outro apenas um, inibindo a capacidade de desenvolvimento de ambos. Comumente, a simbiose é verificada na relação entre mãe-bebê, visto que nesta fase da vida a mãe faz tudo pela criança, mesmo que ela não saiba ou precise. Por vezes, a simbiose 
prolonga-se no decorre do tempo, com a mãe esquecendo-se que tem marido ou até de si própria, colocando o filho sempre em primeiro lugar. Por seu turno, o filho torna-se tão dependente que não aprende a fazer nada por si, espelhando-se e apoiando-se no espectro maternal. Consequentemente, há defasagem em seu amadurecimento e desenvolvimento, especialmente quando adulto (Winnicot, 1980).

Desta forma, o sujeito mora com os pais de forma indefinida, mesmo já possuindo renda própria, relacionamento com outras pessoas, carro e renda para que se mantenha muito bem. Por vezes, o indivíduo sai de casa, mas mantém a ligação maternal, com sua genitora cuidando da casa, lavando suas roupas e fazendo a comida. Dentro da relação simbiótica não há unidade: são dois meios que fazem um, o que causa intempéries. Winnicot (1980) defende que a mãe deve ser ausente para que a criança erre e aprenda o necessário para a vida. Se a mãe falha em falhar, o filho terá grandes consequências em seu desenvolvimento (Sieiro, 2008).

Contudo, no diálogo em que a mãe de Cazuza está a limpar a casa onde o filho reside, após ter saído da casa dos pais. A mãe se depara com uma expressiva quantidade de maconha, sem titubear, pega tudo e joga na 'privada'... e Cazuza ao se deparar com a mãe estabelece o diálogo:

[...] Merda! Você é louca? - Não sou, não!- Você é sim! Você queima dinheiro! - Se for para o teu bem!- O que você sabe sobre o meu bem? - Tudo Cazuza! - A maconha que você jogou fora valia muita grana!- Eu pago!- Vai tomar no "cú"!

Em uma cena seguinte, Cazuza está em um viaduto com o carro parado, sem gasolina. Sua mãe chega rapidamente comum galão de combustível, para prestar-Ihe socorro.

[...] - Que que foi mãe? Está azeda porquê? Eu estou sendo um filhinho nota dez para você, hein? Trabalhando... carteira assinada. Dá um desconto! Quer fazer o favor de falar comigo! - "Tá" aí o que você pediu. Não é o que interessa? - O que você tem, porra? - "Tô" tomando "cú"! Eu faço sempre o que você manda. Como foi a última coisa que você mandou... eu continuo tomando no "cú"! Cazuza cai na risada e sua mãe entra no carro. Ele a chama e mostra um isqueiro perto do galão de gasolina. Ele ameaça atear fogo, caso ela não dê um beijo nele. Ela manda ele parar de ser maluco e dá um afetuoso abraço no filho. 
Em outra cena, o Barão Vermelho faz um show ao ar livre, em um pátio de um condomínio. Cazuza está visivelmente embriagado. A apresentação é devastada pelos erros do vocalista. Um morador de um apartamento vizinho reclama do barulho:

[...] - Sai daí cara! Vai aprender a cantar primeiro! Lucinha sai em defesa do filho:- Não está gostando? Fecha a janela!- Oh Dona... nem estou falando com você! Eu só quero dormir. Cazuza fala: Sabe qual é o seu problema? Você nunca bebeu! Oh...baguncinha... não sabe o que está perdendo! $O$ álcool... o pão é a realidade, mas o álcool é a imaginação! Está na Bíblia!

Estas sequencias de cenas reflete um movimento que a enquadra no tipo de família descontrolada - nestas famílias existe um membro com problemas crônicos de comportamento, podendo este ser relacionando com circunstâncias fortuitas da vida, doença ou comportamentos aditivos (esquizofrenia, toxicodependência, alcoolismo, etc.), o que vai condicionar a estrutura familiar conduzindo a dificuldades na organização hierárquica e nas relações interfamiliares. Impõe-se, assim, a necessidade de reorganização a nível funcional e estrutural (Caniço, Bairrada, Rodrigues \& Carvalho, 2010).

A ligação direta do uso de álcool e o comportamento violento é alvo de intensas pesquisas, visto que o uso desta substância favorece a expressão do comportamento violento, além de ser a "porta de entrada" para o consumo de demais psicotrópicos, tais como maconha, cocaína, etc. As bebidas alcoólicas provocam a desinibição do indivíduo, que somada a transtornos referentes à personalidade facilitam e maximizam a formação de um quadro aniquilador (Santos 2013).

Quanto às relações conjugais a família é um sistema dinâmico criado e condicionado pelas relações entre os membros que a compõem, englobando relações conjugais e parentais. Os tipos de família não são imutáveis, estanques. A relação conjugal é parte importantíssima no que diz respeito à origem da família, constituindo união e reforço de objetivos comuns em harmonia, utilidade e sociedade. É inevitável e análise da dinâmica entre os cônjuges para compreender qual a repercussão que tem sobre os restantes membros da família (Caniço, Bairrada, Rodrigues \& Carvalho, 2010).

$\mathrm{Na}$ cena em que os pais de Cazuza o buscam na cadeia, visto que foi preso por seus atos de libertinagem, o protagonista recusa-se a sair sem os amigos, impondo aos pais que paguem a fiança de todos. 
[...] - Chegaram... chegaram..os anjos da guarda mais eficientes do Rio de Janeiro. Meu rei e minha rainha!- Ai Cazuza! Meu filho, vamos embora..anda!- Vossa côrte! Um time de vagabundos aprovados nas piores mesas da cidade! [...]- Vamos embora, Cazuza!- Não, não! Isto é impossível! Eu não vou sair daqui sozinho! Os meus amigos vão comigo!

Na cena posterior, Lucinha fala ao seu marido:

[...] - Está vendo o que dá passar tanto tempo fora de casa? - Agora não, Lucinha!- Pra você é fácil não é Julio? Sai cedo... chega tarde... Estou cansada de ficar regulando o Cazuza sozinha! Você tem que conversar com ele! E é já!

As cenas mencionadas apontam para uma relação conjugal familiar tradicional, estruturada em função do gênero masculino e feminino, diferenciados. Cada membro possui papel pré-estabelecido dentro da família e na sociedade, consoante o gênero e/ou faixa etária, conservador no tempo e atitude. Isso condiciona sobrecarga de algum/alguns dos membros e desvalorização de atividade produzida. A submissão limitativa da individualidade, a hierarquia prepotente e a perda da identidade são riscos para instabilização familiar (Caniço, Bairrada, Rodrigues \& Carvalho, 2010).

O modelo de família tradicional no Brasil e no mundo é a de maior prevalência entre as relações conjugais. Em determinado tempo, a família tradicional configurava-se como àquela na qual o homem era o único provedor, trabalhando fora, enquanto a mulher cuidava da casa e dos filhos sem ser remunerada. Atualmente, as pessoas asseveram sobre a família tradicional com demais alternativas: a união pode ser legal ou consensual; a família pode ou não ter filhos; o vínculo matrimonial pode ser desfeito por divórcio ou reconstituído em demais matrimônios; o homem deixa de ser o provedor e o casamento passa a ser igualitário, com careira para ambos os cônjuges e até mesmo residência em lugares distintos; o casal pode ser hétero ou homossexual; bem como a casa pode contar com habitação comunal, de famílias extensas e multigeracionais (Carnut \& Faquim, 2014).

É fato que o modelo tradicional de família gerou uma infinidade de outros modelos familiares, os quais possuem diferenças no padrão nuclear tradicional, ou seja: pai, mãe e filhos. Essas alterações constituem a base histórica social. Cada vez mais os papéis familiares são difusos, ao contrário de outrora, tempo no qual eram rigidamente definidos (Oliveira, 2009).

Rev. Psicol Saúde e Debate. Dez., 2017:3(2):74-89. 
Quanto as relações parentais, está se traduz afeto, autoridade, capacidade de controle e flexibilidade. Analisam-se as dinâmicas entre as diferentes gerações que compõem as famílias, a educação e a transmissão de valores por parte dos pais aos filhos e a recepção desta informação por parte dos filhos (Caniço, Bairrada, Rodrigues \& Carvalho, 2010).

O filme aborda uma relação parental demarcada pela instabilidade nos tipos identificados de relações parentais. A instabilidade é compreendida como a ausência de constância, ou seja, aquilo que oscila. A família é a grande responsável por difundir a estabilidade nas relações humanas. Assim sendo, uma família na qual os indivíduos reproduzem um comportamento estável é decorrente de um estilo de vida firme/sólido; por outro lado, a instabilidade familiar origina-se de indivíduos cujos comportamentos são imprevisíveis, por vezes necessitando de ajuda médica. Os distúrbios familiares, em sua grande maioria, têm origem em problemas econômicos, de uso de entorpecentes, alcoolismo e violência doméstica (Paula, 2013). Há também a presença do anseio contemporâneo de acúmulo de capital, no qual se constata a valorização do efêmero, da novidade e da fluidez nas relações, o que proporciona grande instabilidade e fragilidade das relações afetivas e familiares (Lino, 2009).

No filme constata-se uma família superprotetora - marcada por preocupação excessiva em proteger os filhos/as, sendo os pais supercontroladores, não permitindo o desenvolvimento e autonomia dos filhos/as, criando-lhes uma redoma. Os filhos não aprendem a "ganhar a vida", são contagiados pelos medos dos pais e sentem a necessidade de se defender de forma exagerada e apresentam desculpas para tudo. Os pais atrasam o amadurecimento dos filhos/as, tornando-os extremamente dependentes das suas decisões não partilhadas (Caniço, Bairrada, Rodrigues \& Carvalho, 2010). Na cena onde Cazuza sai de casa, após uma briga com os pais, o casal dialogam:

[...] - Ele só saiu de casa, Lúcia! Já estava até passando da hora! - Pode ser, mas não me peça para gostar.- A gente não gosta de tudo... ele vai aprender a andar sozinho. - Tenho medo que ele se machuque.

Identificado pela passagem da cena onde o pai de Cazuza entra em seu banheiro e declara:

[...] - O que eu faço com você, hein?- Olha... não esquece de por gasolina. - Eu perguntei o que eu faço com você?!- Deixa que eu faço sozinho, pai! - Sozinho você ainda

Rev. Psicol Saúde e Debate. Dez., 2017:3(2):74-89. 
estava na delegacia. - Saiu muito caro?- O assunto não é dinheiro, Cazuza! Aliás, dinheiro com amigos é sempre um caso. O negócio é saber aonde você quer chegar. Você quer chegar em algum lugar?- Olha, eu "tava" na praia, fui pra delegacia. Agora eu estou aqui. São três lugares em que eu cheguei. - Você sabe do que eu estou falando!

[Neste ato, Cazuza pega uma garrafa de bebida alcoólica e começa a beber, mesmo ainda sendo manhã.]

- Sei. Poltrona de couro, ar condicionado, diploma, abotoadura, perfume, conta pra pagar...- E eu pago. As minhas e as suas. - Você disse que o assunto não era dinheiro!- $O$ assunto é o que se faz pra ganhar dinheiro.- Ah pai... eu me divirto.. Eu amo meus amigos! Eu não faço mal a ninguém!- $O$ problema não é só o mal que a gente pode fazer para os outros. Mas aquele que a gente faz pra si mesmo. - Ai que "ta" Big John. Eu preciso dos meus amigos para me proteger.

As cenas apresentadas destacam um tipo de família permissiva - cujo os pais não são capazes de disciplinar os filhos. Procuram racionalizar os seus comportamentos, evitando o autoritarismo, acabando por permitir-lhes fazer o que querem, por demissão parental e/ou egocentrismo em relação ao núcleo familiar. Nestas famílias, os pais não funcionam como pais, nem os filhos funcionam como tal e, com frequência, observa-se crescente controle dos filhos sobre os pais em atitude, atingindo a violência verbal ou física. Em casos extremos, os pais perdem toda a autoridade, com medo das reações dos filhos. Os filhos transportam o seu poder para o círculo de amigos e social, deslocando objetivos, podendo exercer liderança negativista ou tornar-se irascíveis (Caniço, Bairrada, Rodrigues \& Carvalho, 2010).

A superproteção pode ser caracterizada como o cuidado em excesso, o que resultará em um bloqueio no desenvolvimento e no aprendizado, visto que a criança será inibida de explorar o mundo, frustrando-se com o passar do tempo, gerando problemas sociais e afetivos. A superproteção não está relacionada diretamente com deficiência, mais sim com medo do mundo e da violência. Quando os pais têm dificuldade em dar liberdade à criança, facilitando as tarefas cotidianas, as impede de desempenhar as atividades de modo autônomo e capaz, sendo um fator impeditivo para o crescimento adequado do indivíduo (Cavalcanti, Silva \& Porto, 1990).

Estudos apontam que relações superprotetoras e permissivas entre pais e filhos são ocasionadas por fatores como: violência, desestruturação familiar, uso de entorpecentes, Rev. Psicol Saúde e Debate. Dez., 2017:3(2):74-89. 
novas tecnologias, inserção da mulher no mercado de trabalho, o filho único e a compensação da carência e falta de tempo através de bens materiais Estes fatores somam para a formação de um novo contexto social, que no anseio de educar os filhos de maneira eficiente, desencadeia o abuso psicológico de superproteção. Os pais, por vezes, não reconhecem a "falha" na aprendizagem e criação de seus filhos, manifestando a proteção excessiva de maneira involuntária (Cavalcanti, Silva \& Porto, 1990).

Cazuza sabia que a mãe vivia por ele, aproveitando-se desta 'doação' para viver a vida como bem entendia. Lucinha não negava absolutamente nada ao filho, mesmo que isto ferisse seus princípios e as regras de conduta da época. Lucinha vê, ao raiar do dia, um homem deixando sua casa, após ter passado a noite com Cazuza. E logo que chega para tomar café e a saúda:

[...] - Bom dia, minha passarinha!- Bom dia, meu bem! Por que ela não ficou para tomar café? - Ela quem? - Ué, a garota que dormiu com você!- Não tinha garota nenhuma. "Tá" me vigiando, é? - "Tô". Por que você não é como os outros, hein Cazuza?- Porque os outros, mãe, são cheios de defeitos. Ahhh... e você não?- Não. Eu não. Que defeito? Que defeito... sou seu filho único. Pura perfeição!

Em um bar com os amigos, Cazuza começa a falar sobre a relação materna:

[...] - Acontece que as mães têm que parir duas vezes. Uma quando a gente nasce e outra quando a gente cresce. $A$ segunda é mais difícil. Malú, uma amiga, indaga: - Difícil pra quem?Cazuza responde: - Para todos nós.

As cenas contextualizada acima configuram-se em uma relação parental de família centrada nos filhos, cuja os pais não sabem enfrentar os seus próprios conflitos conjugais que desvalorizam sem avaliação e ajustamento. Desta forma, em vez de procurar resolver os problemas, centram a atenção em temas e gestos relacionados com os filhos, o que pode tornar-se o seu único assunto de conversa e interesse. Estes pais procuram insistentemente a companhia dos filhos, alternativa essencial para a sua satisfação e motivo de vida. Podem definir-se como pais que vivem para e pelos seus filhos (Caniço, Bairrada, Rodrigues \& Carvalho, 2010).

O filme retrata pai de Cazuza em diversas partes cenas em excesso de trabalho, sendo ausente em casa. Cazuza percebia isso e apontava ao do pai, buscando não viver a mesma vida, considerada por ele como um insucesso de vida. Este contexto aponta para a família centrada nos pais. Neste tipo de família, as prioridades dos pais focalizam-se nos Rev. Psicol Saúde e Debate. Dez., 2017:3(2):74-89. 
projetos pessoais individuais, sejam eles profissionais e/ou lúdicos. Em consequência, o tempo partilhado com os filhos é escasso, assim como a transmissão de valores e afeto é subvalorizada. Trata-se de uma relação baseada no ato material, refúgio para suplantar a carência afetiva por parte dos progenitores para com os seus filhos, seja este fato por indisponibilidade e/ou interesse (Caniço, Bairrada, Rodrigues \& Carvalho, 2010).

A ausência paterna possui potencial para gerar conflitos no desenvolvimento psicológico da criança, defasando o desenvolvimento cognitivo e desencadeando distúrbios de comportamento, como o mau desempenho escolar. Um fator relevante para ser elencado nesta situação de ausência é a aproximação ou rejeição perante a figura materna. $O$ relacionamento entre mãe e filho pode desencadear em uma maior ou menos predisposição para os conflitos relacionados à falta do pai, sendo esta relação como uma mediadora das repercussões da vida emocional do sujeito. Há também colaboração do ambiente familiar como um todo (presença de irmãos, tios e avôs), social e econômico (Erizik \& Bergmann, 2004).

A falta de um modelo na educação, seja masculino ou feminino, implica em um desequilíbrio naquele que é educado, ou seja, no filho. A presença paterna é diferente e complementar à materna. Os filhos necessitam de apoio e segurança, sendo na juventude o pai um modelo no qual o jovem se inspira. Caso o pai se ausente, os modelos que virão ocupar o espaço vago podem não ser os ideais (Benczik, 2011).

\section{CONSIDERAÇÕES FINAIS}

A inserção das drogas, através do usuário, dentro do núcleo familiar, modifica exponencialmente não só aquela coletividade de pessoas, mas sim grande parcela de toda sociedade. Os narcóticos são disseminadores de problemas sociais, como perda do emprego e desestruturação familiar; além de trazer à tona diversas patologias.

A análise do filme "Cazuza - o tempo não para" foi primordial para a compreensão da temática. Este caso verídico e notório da sociedade brasileira demonstra, de forma límpida, como a família pode influenciar o indivíduo a procurar atividades ilícitas. A superproteção materna e em contrapartida a ausência paterna, além do acesso fácil a dinheiro, dentre outros fatores, incidiram diretamente em todas as atitudes rebeldes de Cazuza. As drogas foram determinantes para que caísse na vida boêmia e não se cuidasse, tornando-se aidético.

Rev. Psicol Saúde e Debate. Dez., 2017:3(2):74-89. 
O estudo teve como proposta abordar a linha tênue que liga as relações familiares e o uso de entorpecentes. Ficou evidente, que o núcleo familiar é fator determinante para as escolhas de cada pessoa, visto que é na família que o indivíduo possui seus exemplos, sejam negativos ou positivos.

Desta forma, o trabalho em conjunto de toda sociedade, principalmente com o intuito de preservar a instituição familiar, é imprescindível para que as drogas não desestruturem mais toda comunidade. O exemplo de Cazuza deve ser recordado, para que não aconteça com outros inúmeros brasileiros.

Necessário se faz o trabalho do psicólogo com todos os membros da família, não só o usuário. As consequências do uso de narcóticos atingem a cada ente familiar de forma específica.

\section{REFERÊNCIAS}

Araújo A. \& Echeverria R. (2016). Cazuza: só as mães são felizes. 2. ed. São Paulo: Globo.

Benczik E. B. P. (2011). A importância da figura paterna para o desenvolvimento infantil. Revista de Psicopedagogia, 28(85):1-9.

Caniço H., Bairrada P., Rodriguez E. \& Carvalho A. (2010). Novos tipos de Família: plano de cuidados. Imprensa da Universidade de Coimbra.

Carnut L. \& Faquim J. (2014). Conceitos de família e a tipologia familiar: aspectos teóricos para o trabalho da equipe de saúde bucal na estratégia de saúde da família. Journal of Management \& Primary Health Care, 5(1):1-9.

Cavalcanti A. B., Silva S. J. G. \& Porto Z. G. (1990) Percepções parentais da superproteção na educação infantil. Universidade Federal de Pernambuco.

Ezirik M. \& Bergmann D. S. (2004). Ausência paterna e sua repercussão no desenvolvimento da criança e do adolescente: um relato de caso. Revista de Psiquiatria do Rio Grande do Sul, 26(3): 1-7.

Fonseca J. (2012). Onde está o reconhecimento do ele na matriz de identidade? Intersecções entre Moreno e Lacan. Revista Brasileira de Psicodrama, 20(1):115-34.

Freitas A. P. C. O. (2008). Práticas educativas parentais em relação ao filho único e ao primogênito em famílias com dois filhos. (Dissertação de Mestrado). Universidade Federal do Rio Grande do Sul, Porto Alegre, RS, Brasil. 
Lino M. V. A. (2009). Contemporaneidade e seu impacto nas relações familiares. Revista IGT na Rede, 6(10):2-13.

Marques A. C. P. R. \& Cruz M. S. (2000). O adolescente e o uso de drogas. Revista Brasileira de Psiquiatria, 22(Supl II):32-39.

Oliveira N. H. D. (2009). Família contemporânea. São Paulo: Editora UNESP.

Orth A. P. S. (2005). A dependência química e o funcionamento familiar à luz do pensamento sistêmico. (Dissertação de Mestrado). Centro de Filosofia e Ciências Humanas, Florianópolis, SC, Brasil.

Padilha A. S. (2011). O lugar da família e a dependência química. (Trabalho de conclusão de curso). Universidade Regional do Noroeste do Estado do Rio Grande do Sul, Ijuí, RS, Brasil.

Paula L. (2013). A família no contexto social. Câmara Legislativa do Distrito Federal.

Penso M. A. \& Subdrack M. F. (2004). Envolvimento em atos infracionais e com drogas como possibilidades para lidar com o papel de filho parental. Revista de Psicologia USP, 4(3): 2954.

Santos C. C. (2013). Fatores predisponentes ao comportamento violento em portadores da síndrome da dependência alcoólica atendidos em um centro de referência em dependência química. (Dissertação de mestrado). Universidade Federal de Pernambuco, Recife, PE, Brasil.

Schenker M. \& Minayo M. C. S. (2003). A implicação da família no uso abusivo de drogas: uma revisão crítica. Revista de Ciências e Saúde Coletiva, 8(1):299-306.

Sieiro A. (2008). Simbiose. Associação Livre.

Tavares M. B., Fuchs F. C., Diligenti F., Abreu J. R. P., Rohde L. A. \& Fuchs S. C. (2004). Características de comportamento do filho único VS filho primogênito e não primogênito. Revista Brasileira de Psiquiatria, 26(1):17-23.

Werneck S. \& Carvalho W. (2004). Cazuza - O tempo não pára. [DVD]. São Paulo: Sony Pictures.

Winnicott D. W. (1980). A família e o desenvolvimento do indivíduo. Belo Horizonte: Interlivros. 